\title{
Case report: a subject with a mutation in the ATG start codon of L-ferritin has no haematological or neurological symptoms
}

\author{
L Cremonesi, A Cozzi, D Girelli, F Ferrari, I Fermo, B Foglieni, S Levi, C Bozzini, M Camparini, \\ M Ferrari, P Arosio
}

J Med Genet 2004;41:e81 (http://www.jmedgenet.com/cgi/content/full/41/6/e81). doi: 10.1136/jmg.2003.011718

$F^{\prime}$ erritin consists of two subunit types, $\mathrm{H}$ and $\mathrm{L}$, which assemble in different proportions in a 24-mer protein. The H-subunit has ferroxidase activity and is mainly found in cell cytoplasm, where it has the major function of sequestering and detoxifying unwanted iron. The L-subunit has no catalytic activity on its own, but assists the functionality of the H-subunit ${ }^{2}$ and is also found in minor amounts in serum. ${ }^{3}$ Two types of genetic disorder are associated with mutations of the L-ferritin gene $(F T L)$, both with autosomal dominant transmission. The first, hereditary hyperferritinaemia cataract syndrome (HHCS), is caused by mutations in the regulatory iron responsive element (IRE) in the 5'UTR of the transcript that reduce binding affinity to the iron regulatory proteins (IRPs) and lead to constitutive upregulation of the protein in tissue and serum. ${ }^{4-8}$ Subjects with the mutations show high levels of serum ferritin (500$2000 \mu \mathrm{g} / \mathrm{l}$ ) and often early-onset bilateral cataracts ${ }^{6}$ likely caused by protein aggregation in the lens, ${ }^{9}$ but do not present alterations in iron metabolism. The disorder has been extensively studied and more than 21 different causative mutations have been identified. ${ }^{9}{ }^{10}$ The second type of genetic disorder, neuroferritinopathy, is rare and few families have been identified. It is associated with an adenine insertion at position 460-461 in the coding region (exon 4) of the gene that causes a frame shift alteration of the C-terminus of the L-ferritin polypeptide. ${ }^{11}$ Affected subjects show late-onset movement disorders, iron deposition in the brain basal ganglia, and low serum ferritin levels. ${ }^{12}{ }^{13}$ It is unclear whether the iron deposition in the brain is caused by a quantitative defect of L-ferritin or by an abnormal functionality caused by the specific mutation. Another type of hereditary ferritinopathy has been reported. $^{14}$ It is an autosomal dominant neurodegenerative disorder characterised by intra-cytoplasmic and intra-nuclear accumulation of ferritin in the central nervous system, but its genetic causes have not been clarified. Here we report the identification of a heterozygous mutation of the first nucleotide of the L-ferritin start codon in a control subject who participated in a screening study of subjects at risk of HHCS. The subject showed low levels of ferritin in serum and tissues, but was free of any haematological or neurological symptoms. The data suggest that L-ferritin haploinsufficiency is not the cause of movement disorders.

\section{METHODS}

Subjects were enrolled in a case-control study aimed at investigating the association between mutations in the Lferritin IRE and the occurrence of cataracts. DNA analyses were performed in 292 subjects ( 177 with cataracts and 115 controls with clear lenses) participating in the Collaborative Italian-American Clinical Trial of Nutritional Supplements and Age-Related Cataract. The procedures for DNA prepara-

\section{Key points}

- Mutations of the L-ferritin gene (FTL) are associated with two types of dominant genetic disorder: hereditary hyperferritinaemia cataract syndrome caused by modifications of the iron responsive element in the $5^{\prime}$ UTR which upregulate ferritin expression, and hereditary neuroferritinopathy caused by an adenine insertion at position 460-461 of the mRNA coding region.

- We report the identification of the heterozygous mutation $1 \mathrm{~A} \rightarrow \mathrm{G}$ which alters the ATG start codon in a healthy control subject with normal haematological indices and no signs of neurological or movement disorders, but with low levels of L-ferritin in serum and in blood cells.

- The data indicate that haploinsufficiency of L-ferritin protein has no evident clinical effects on systemic iron metabolism, and suggest that the defects caused by the FTL mutation in neuroferritinopathy probably originate from abnormal properties of the altered protein.

tion, PCR amplification, DHPLC analysis, and DNA sequencing have been already described by Cremonesi et al. ${ }^{10}$ Ferritin in blood cell extracts was determined with specific $\mathrm{H}$ - and Lferritin ELISA assays calibrated on recombinant $\mathrm{H}$ - and Lhomopolymers. ${ }^{15}$

\section{RESULTS AND DISCUSSION}

DNA variations in the $5^{\prime}$ UTR of L-ferritin were analysed in a cohort of 292 subjects who participated in a control study on the incidence of HHCS in subjects with cataracts. The participants consisted of 177 subjects with cataracts and 115 healthy controls. One of the subjects showed an abnormal DHPLC pattern (fig 1A) indicating the presence of a mutation. This was confirmed by sequence analysis that showed an $1 \mathrm{~A} \rightarrow \mathrm{G}$ substitution causing the first Met codon to change into a Val (fig 1B). The L-ferritin transcript does not have any ATG upstream of the start codon and the improbable use of the next in-frame ATG (Met-69) would encode a non-functional and unstable protein of 106 amino acids. Therefore the $A \rightarrow G$ mutation was predicted to disable protein translation and expression. The mutation seems to be rare and was not found in an additional 1006 patients at risk for haemochromatosis or HHCS and screened for the same DNA region (not shown). The subject was a 52 year old

Abbreviations: HHCS, hyperferritinaemia cataract syndrome; IRE, iron responsive element; IRP, iron regulatory protein 


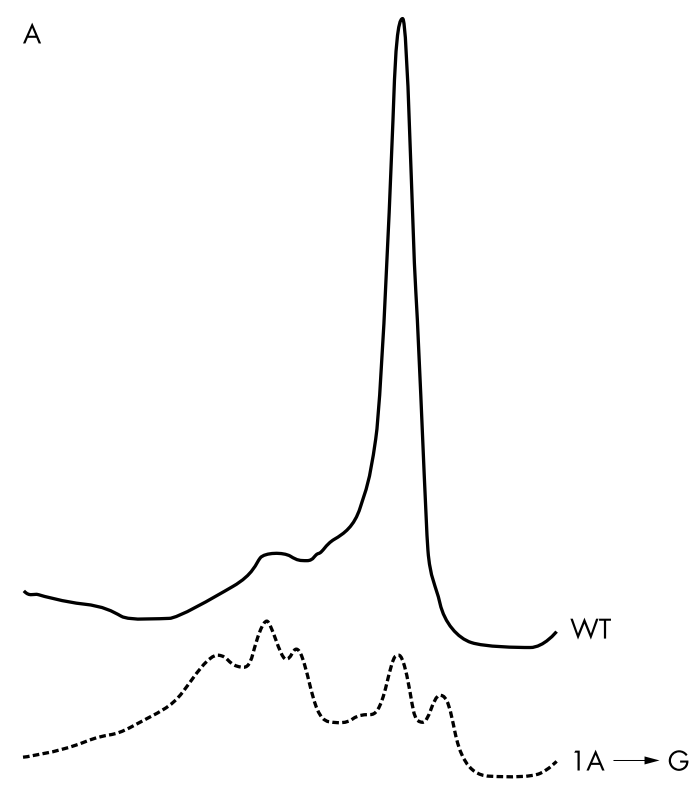

B

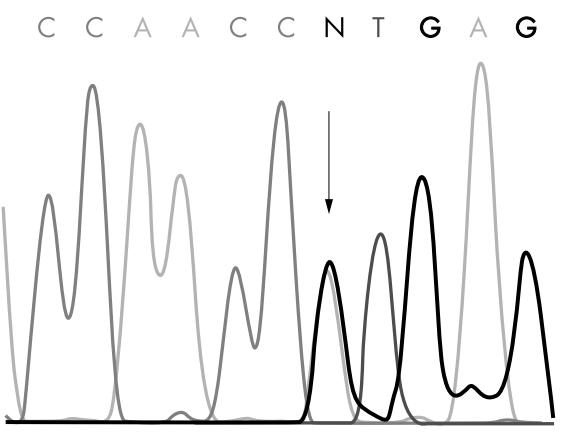

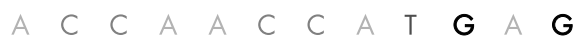

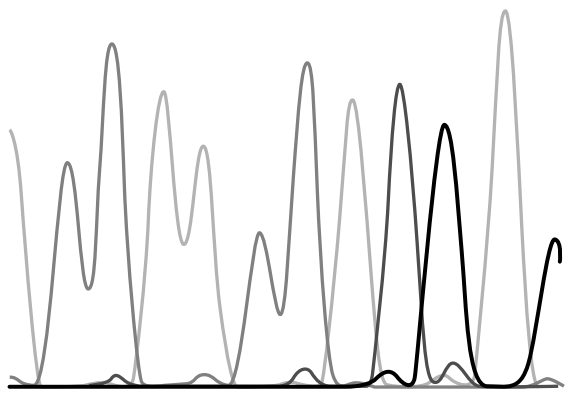

Figure 1 Identification of the $A \rightarrow G$ mutation. (A) DHPLC chromatograms of 197A $\rightarrow G$ mutant DNA compared to wild type DNA (WT). Samples (5 $\mu$ l) for PCR amplification of DNA heterozygous for the indicated mutations were run at $64^{\circ} \mathrm{C}$ under the same conditions. The traces of the mutant DNA show extra components and are easily distinguished from the more symmetric profile of the wild type DNA. (B) DNA sequence analysis of the new mutations. The chromatogram of the mutant DNA (upper) is compared with the corresponding wild type DNA (lower); the position of the mutations is indicated by the arrow.

woman with no history of iron-deficient anaemia, pregnancy, regular blood donations, or gastrointestinal diseases associated with blood loss. Family history did not reveal any genetic disease, particularly with respect to neurological or movement disorders. The woman was in good health with the exception of mild hypertension treated with a low-dose $\beta$-blocker and diuretics. Haematological examinations showed normal levels of haemoglobin $(14.4 \mathrm{~g} / \mathrm{dl})$, MCV $(88.5 \mathrm{fl})$, and iron indices (serum iron $70 \mu \mathrm{g} / \mathrm{l}$; transferrin saturation $17 \%$ ), with the relevant exception of serum ferritin levels, which were low $(12.7 \mu \mathrm{g} / \mathrm{l})$. In agreement with normal haemoglobin and MCV, the normal levels of serum transferrin receptor ( $1.61 \mathrm{mg} / \mathrm{l}$; range $0.8-1.8$ ) ruled out the presence of true iron deficiency. A detailed family study could not be performed. To evaluate whether the low serum ferritin levels unrelated to body iron stores were caused by the genetic effect we measured ferritin levels in the most easily obtainable tissue, that is blood cells. In two independent determinations we found that $\mathrm{H}$-ferritin concentrations in the subject and a healthy control were comparable (mean values $1000 \vee 1400 \mathrm{ng} / \mathrm{g}$ protein, respectively), while that of L-ferritin was greatly reduced in the subject $(47 v 340 \mathrm{ng} / \mathrm{g}$, respectively). The ratio between $\mathrm{L}$ - and $\mathrm{H}$-ferritin in the control was 0.24 , consistent with the figures reported by Piperno et al, ${ }^{16}$ while the index in the subject was 0.047, which is about five fold lower. For ethical reasons, brain MRI for investigation of iron deposition in basal ganglia could not be performed.

Present data indicate that the inactivation of one FTL allele causes a significant reduction of L-ferritin in serum and blood cells. This was expected, since mice with an inactivated $\mathrm{H}$-ferritin allele showed low $\mathrm{H}$-ferritin levels in all tested tissues. ${ }^{17}$ More important is the observation that genetic L-ferritin deficiency (in the present case) or excess (in HHCS) has no evident effect on systemic iron metabolism ${ }^{7}$ indicating that L-ferritin levels do not regulate iron homeostasis. In neuroferritinopathy all subjects with the L-ferritin mutation develop movement disorders typically in the fourth to fifth decades, with some as early as in the late teens, and the disease is considered fully penetrant by the age of $60 .^{11-13}$ The 52 year old woman we described had no neurological or movement abnormalities and none were reported in her family. The observation suggests that the $A \rightarrow G$ substitution in codon 1 of L-ferritin did not cause the abnormal iron deposition in the basal ganglia of the brain typical of neuroferritinopathy, although this cannot be completely excluded as abnormal iron deposition might develop at a later age. This mutation is predicted to simply disable protein expression, while the A insertion found in neuroferritinopathy is predicted to cause the expression of a protein structurally different from wild type L-ferritin, which may interfere with ferritin functionality and with cellular iron homeostasis. In conclusion, the present case report suggests that neuroferritinopathy is not a consequence of haploinsufficency of L-ferritin protein, but more likely a gain-offunction caused by the predicted abnormal C-terminus of the protein.

\section{Authors' affiliations}

L Cremonesi, F Ferrari, B Foglieni, M Ferrari, Genomics for the Diagnosis of Human Pathologies Unit, IRCCS H. San Raffaele, Via Olgettina 58, 20132 Milan, Italy

A Cozzi, S Levi, Protein Engineering Unit, IRCCS H. San Raffaele, Via Olgettina 58, 20132 Milan, Italy

D Girelli, C Bozzini, Department of Clinical and Experimental Medicine, University of Verona, Policlinico G.B. Rossi, 37134 Verona, Italy I Fermo, Separative Techniques Unit, IRCCS H. San Raffaele, Via Olgettina 60, 20132 Milan, Italy

M Camparini, Section of Ophthalmology, University of Parma, 43100 Parma, Italy

P Arosio, Section of Chemistry, Faculty of Medicine, University of Brescia, 25100 Brescia, Italy

This work was partially supported by MIUR-Cofin grants to PA, a MIURCofin grant to PA and SL, and by Telethon-ltaly Grant GP0075Y01 to SL. Conflict of interest: none declared. 
Correspondence to: Professor Paolo Arosio, Department MITB, Viale Europa 11, 25125 Brescia, Italy; arosio@med.unibs.it

Received 23 July 2003

Accepted for publication 31 July 2003

\section{REFERENCES}

1 Harrison PM, Arosio P. The ferritins: molecular properties, iron storage function and cellular regulation. Biochim Biophys Acta 1996;1275:161-203.

2 Santambrogio P, Levi S, Cozzi A, Rovida E, Albertini A, Arosio P. Production and characterization of recombinant heteropolymers of human ferritin $\mathrm{H}$ and $\mathrm{L}$ chains. J Biol Chem 1993;268:12744-8.

3 Santambrogio P, Cozzi A, Levi S, Arosio P. Human serum ferritin G-peptide is recognized by anti-L ferritin subunit antibodies and concanavalin-A. Br J Haematol 1987:65:235-7.

4 Beaumont C, Leneuve P, Devaux I, Scoazec JY, Berthier M, Loiseau MN, Grandchamp B, Bonneau D. Mutation in the iron responsive element of the $L$ ferritin mRNA in a family with dominant hyperferritinaemia and cataract. Nat Genet 1995; 11:444-6.

5 Girelli D, Corrocher R, Bisceglia L, Olivieri O, De Franceschi L, Zelante L, Gasparini P. Molecular basis for the recently described hereditary hyperferritinemia-cataract syndrome: a mutation in the iron responsive element of ferritin L-subunit gene (the "Verona mutation"). Blood 1995:86:4050-3.

6 Girelli D, Bozzini C, Zecchina G, Tinazzi E, Bosio S, Piperno A, Ramenghi U, Peters J, Levi S, Camaschella C, Corrocher R. Clinical, biochemical, and molecular findings in a series of families with hereditary hyperferritinaemiacataract syndrome. Br J Haematol 2001;115:334-40.

7 Levi S, Girelli D, Perrone F, Pasti M, Beaumont C, Corrocher R, Albertini A Arosio P. Analysis of ferritins in lymphoblastoid cell lines and in the lens of subjects with hereditary hyperferritinemia-cataract syndrome. Blood 1998:91:4180-7.
8 Cazzola M. Hereditary hyperferritinaemia/cataract syndrome. Best Pract Res Clin Haematol 2002;15:385-98.

9 Brooks DG, Manova-Todorova K, Farmer J, Lobmayr L, Wilson RB, Eagle RC Jr, St Pierre TG, Stambolian D. Ferritin crystal cataracts in hereditary hyperferritinemia cataract syndrome. Invest Ophthalmol Vis $\mathrm{Sci}$ 2002;43(4):1121-6.

10 Cremonesi L, Paroni R, Foglieni B, Galbiati S, Fermo I, Soriani N, Belloli S, Ruggeri G, Biasiotto G, Cazzola M, Ferrari F, Ferrari M, Arosio P. Scanning mutations of the $5^{\prime}$ UTR regulatory sequence of $L$ ferritin by denaturing HPLC: identification of new mutations. Br J Haematol 2003;121(1):173-9.

11 Curtis AR, Fey C, Morris CM, Bindoff LA, Ince PG, Chinnery PF, Coulthard A Jackson MJ, Jackson AP, McHale DP, Hay D, Barker WA, Markham AF, Bates D, Curtis A, Burn J. Mutation in the gene encoding ferritin light polypeptide causes dominant adult-onset basal ganglia disease. Nat Genet 2001;28(4):350-4.

12 Crompton DE, Chinnery PF, Fey C, Curtis AR, Morris CM, Kierstan J, Burt A, Young F, Coulthard A, Curtis A, Ince PG, Bates D, Jackson MJ, Burn J. Neuroferritinopathy: a window on the role of iron in neurodegeneration. Blood Cells Mol Dis 2002;29(3):522-31.

13 Chinnery PF, Curtis AR, Fey C, Coulthard A, Crompton D, Curtis A, Lombes A, Burn J. Neuroferritinopathy in a French family with late onset dominant dystonia. J Med Genet 2003:40(5):e69.

14 Vidal R, Delisle MB, Rascoal O, Ghetti B. Hereditary ferritinopathy. J Neurol Sci 2003;207:1 10-1.

15 Luzzago A, Arosio P, lacobell C, Ruggeri G, Capucci L, Brocchi E, De Simone F, Gamba D, Gabri E, Levi S. Immunochemical characterization of human liver and heart ferritins with monoclonal antibodies. Biochim Biophys Acta 1986;872:61-71.

16 Piperno A, Taddei MT, Sampietro M, Fargion S, Arosio P, Fiorelli G Erythrocyte ferritin in thalassemia syndromes. Acta Haematol 1984;71:251-6.

17 Ferreira C, Santambrogio P, Martin ME, Andrieu V, Feldmann G, Henin D, Beaumont $\mathrm{C}$. $\mathrm{H}$ ferritin knockout mice: a model of hyperferritinemia in the absence of iron overload. Blood 2001;98(3):525-32. 